Original Research

\title{
Using Technical Means and Logistics Principle Applications to Solve Ecological Water Course Accidents
}

\author{
Ol'ga Végsöová1, Samer Khouri', Martin Straka ${ }^{2 *}$, Andrea Rosová ${ }^{2}$, \\ Peter Kačmáry², Miroslav Betuš ${ }^{1}$ \\ ${ }^{1}$ Institute of Earth Resources, BERG Faculty, Technical University of Kosice, Kosice, Slovakia \\ ${ }^{2}$ Institute of Logistics, BERG Faculty, Technical University of Kosice, Kosice, Slovakia
}

Received: 12 July 2018

Accepted: 16 September 2018

\begin{abstract}
Our paper deals with the solution of ecological flood-type accidents and the mitigation of their impacts during their occurrence. The main task is to defeat an accident on a watercourse as soon as possible, efficiently and economically, by arranging a floating boom. Closer specifications of the paper involve the technical use of floating booms and the calculation of the resistance force, which influences the application of a floating boom at a given current velocity. The calculations show that flow and size of a river flow has a direct effect on the size of the force that impinges on a barrage. The maximum river flows are in the time of January and February. The smallest river has flow of about $2.346 \mathrm{~m}^{3} \mathrm{~s}^{-1}$ in this time, and the biggest river has a flow of $28.88 \mathrm{~m}^{3} \mathrm{~s}^{-1}$ in defined time.
\end{abstract}

Keywords: ecological accident; floating boom; watercourse; technical means; logistics principles

\section{Introduction}

In order to protect the surrounding ecosystems, which may be at risk caused by leak accidents of oil and other petrochemical products, dangerous substances must be separated as soon as possible from the environment and prevented from further expansion [1, 2]. Petroleum and petrochemical products are expanding very rapidly, also in depth, across the water. There are used constructions of various adsorption materials built on the principle of the floating boom to limit their expansion. The cleaning itself is then carried out

*e-mail: martin.straka@tuke.sk by, e.g., chemical processes that are also dangerous for nature.

Experts and scientists all around the world are studying the field of environmental accidents and their solutions. We can meet different designs of models, research, and practices that point to the importance of environmental impacts in many professional journals [3-5].

Zey, Nowroozpour, Lachhab, and Martinez proceed further with the aforementioned problems in their paper and they present data and observations about live-bed, laboratory flume tests showing that a porous deflector wall reduces scour depth and height of sediment accumulation. The flume tests used deflector walls angled at $90^{\circ}$ and $30^{\circ}$ to the bank, as well as varying levels of wall porosity. A minimum value deflector- 
wall porosity of $50-75 \%$ is recommended for design. This range ensures minimal scour or accumulation of sediment at the wall and suitable wall performance as a deflector [6].

Another publication in this area describes the simulation of the flexible floating boom movement, which is implemented by introducing a Rigid Module and Flexible Connector (RMFC) multi-body system. The model is finally applied to the simulation of movement of the flexible floating boom in containing industrial gear oil under the combined waves and currents [7].

An interesting study presents the numerical model based on the N-S equations in a mesh frame. The proposed model tracks the outline of the floating boom in motion by using the fractional area/volume obstacle representation technique [8].

Authors Gapingsi, Korbas and Santos in their work developed the mathematical model for a flexible floating boom that is hooked to two boats (unmanned surface vehicles). It is meant to be used for oil spill containment in marine areas [9].

The scientific paper "Numerical modelling and experimentation of oil-spill curtain booms: Application to a harbor" describes oil-spill curtain booms, which are an important response device dedicated to containing and deviating floating pollutants. The hydrodynamic and structural limitations of curtain booms necessitate numerical modelling for efficient usage assessment. A four-step model is proposed and applied during an exercise performed in the Galician region of Spain. Experimental results are used to produce a re-analysis of the model and improve contingency planning [10]. Many authors deal with algorithmization, planning and logistics in professional journals for the necessity of an environment solution [11-17].

Tsang deals with winter flow and ice conditions on the St. Clair and Detroit Rivers, probability of winter oil spills, effects of ice on winter oil spillage and containment and recovery of spilled oil from the rivers under winter conditions in his study. The study shows that oil and ice may be separated and that the oil is contained in the floating boom (or booms) properly designed and deployed on the water surface [18].

The study "Hydrodynamics and Capture Efficiency of Plastic Cleanup Booms" is composed of two parts. The first deals with the core technology being optimized is the use of floating booms placed perpendicular to the main ocean plastic flow so it can concentrate plastic debris to a point where it can be extracted, shipped and processed in a cost-effective manner. To investigate the capture efficiency of such a system, TOC conducted model-scaled tests at the Dutch Research Institute Marin [19] and the second part is addressed to better understanding the behavior of such a system in the vertical plane and to calibrate dynamic analysis models as well as Computational Fluid Dynamics (CFD) models, TOC conducted model tests of a portion of the boom at 1:5 scale [20].
This paper includes a review of hydroponic root mats (HRMs) that are ecotechnological wastewater treatment systems where aquatic vegetation forms buoyant filters by their dense interwoven roots and rhizomes, sometimes supported by rafts or other floating materials. A preferential hydraulic flow is created in the water zone between the plant root mat and the bottom of the treatment system. When the mat touches the bottom of the water body, such systems can also function as HRMs filter; i.e., the hydraulic flow passes directly through the root zone. HRMs have been used for the treatment of various types of polluted water, including domestic wastewater; agricultural effluents; and polluted river, lake, stormwater and groundwater, and even acid mine drainage [21].

The solution of the actual problems can also be found in the publication where the core technology is being optimized by the use of floating booms placed perpendicular to the main ocean plastic flow so that it can concentrate on plastic debris to a point where it can be extracted, shipped and processed in a cost-effective manner [22].

Researchers have decided to study the performance of floating booms under waves and currents, which is being investigated by means of genetic programming (GP). This artificial intelligence (AI) technique is used to establish the mathematical expression of the significant effective draft, an essential parameter in predicting the containment capability of floating booms, and more specifically the occurrence of a drainage failure. Obtained by applying GP to a comprehensive dataset of wave-current flume experiments, the expression makes the relationships among the relevant variables explicit - an advantage relative to other AI techniques such as artificial neural networks (ANN) [23].

The paper "Preparing the automatic spill recovery by two unmanned boats towing a boom: Development with scale experiments" studies the control and coordination needs for automatically towing a boom, and proposes the use of unmanned boats with autonomous control [24].

Experts processed the study that is intended to examine the quality and quantity of floating plastic debris in the River Seine through the use of an extensive regional network of floating debris-retention booms; it is one of the first attempts to provide reliable information on such debris on a large regional scale [25].

The scientific paper created by Shi, Li, Chen et al., is focused on a multi-phase smoothed particle hydrodynamics (SPH) method developed to model the failure process of a flexible oil boom. The proposed algorithm is based on the dynamic boundary particles (DBPs) for preventing particle disorders of multi-phase fluid particle movement around a solid boundary [26].

In "Experimental studies on performances of flexible floating oil booms in coupled wave-current flow," the authors deal with the floating oil booms that are a commonly adopted method for collecting spilled oil on the sea surface, or to protect specific areas against oil 
slick spreading. In this study, 931 runs of a laboratory test were carried out under wave-current coupling conditions to investigate hydrodynamic performances of the flexible floating oil boom. The tests first conducted a comparison on motion responses between the flexible floating boom and the rigid one to indicate the necessity of taking the flexibility of the boom into consideration [27].

\section{Theoretical Base}

In the case of the capture of petroleum origin substances at the level of water courses, the procedure is chosen to delimit the floating oil substance as quickly as possible or to prevent its free expansion to the environment effectively, and subsequently to remove it from the water level energetically. There are various types of obstacles constructed, which use the principle of floating booms in the form of a circular-spiral barrier or by laying a perpendicular obstacle into the water flow profile to limit and reduce pollution (Fig. 1).

The applicability and effectiveness of the floating booms depends on the flow of water (water flow speed) and on the occurrence of waves. At a greater water flow, at more than $0.75 \mathrm{~m} / \mathrm{s}$, the formed oil film in front of the boom can be carried along by a stream of water under the plunged edge of the floating boom. Practical applications of the floating booms show that when the oil film thickness reaches two-thirds of the height of the plunged edge of the boom (the height of the plunged boom is usually $10 \mathrm{~cm}$ ), oil drops began pulling down from the formed film by the water flow under the plunged edge of the floating boom.

For these reasons, the efficiency of capturing a petroleum substance from the water level is increased by skewing the boom position on its profile or by inserting several booms consecutively on one profile. In the case of the use of a skew boom, the effect of a sluice of the formed oil film along its boom to a watercourse bank is used, where an oil substance can be handled better.

The floating boom is a device for capturing escaped harmful substances, mostly petroleum products from the water surface. Typically, this is an articular T-shaped solid wall made of wood or light, solid metal blocks or a $30 \mathrm{~cm}$ diameter single-chamber plastic air tube, or a two-chamber plastic wall where one chamber is below the water level. The floating boom can be provided with a flashboard, fixed foil (Fig. 2). Inflatable walls consist of $5 \mathrm{~m}$ and $10 \mathrm{~m}$ segments or an endless strip 100 or $200 \mathrm{~m}$ long; solid walls are made of prefabricated wood or lightweight metal or polyurethane foam-filled segments of 2-5 m lengths joined together to form a strong floating boom. The segments are joined as required to the width of a watercourse.

It is convenient to apply sorption materials to water surface to create suspensions in order to increase the effect of removing entrained floating petroleum substances on the front side of the floating boom. It can be easier to manipulate with this form of suspension when picking up with a strainer ladle or a bar screen. In the past, natural materials such as straw, peat, wood sawdust and shavings were used for this purpose. These materials are currently being replaced by special
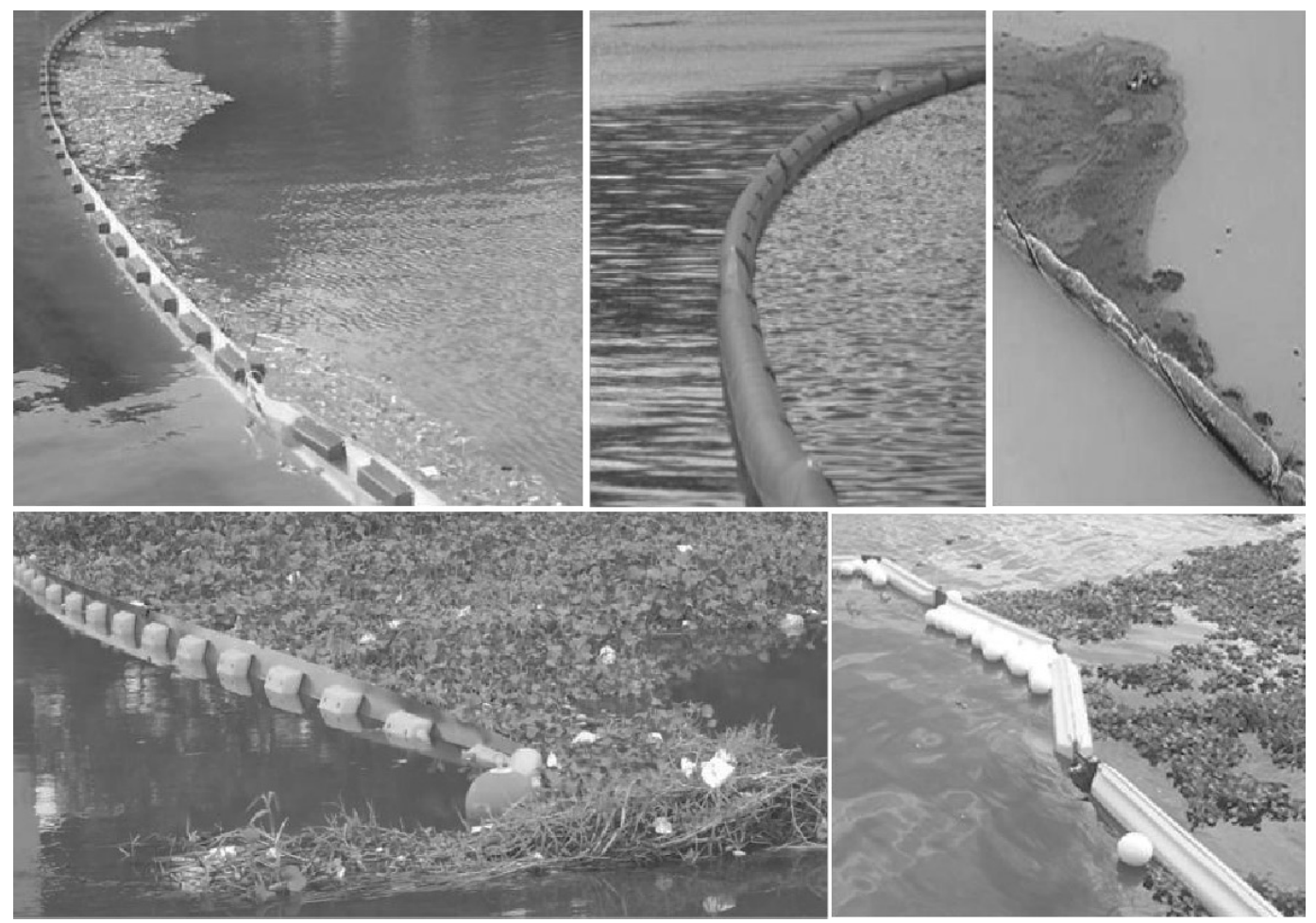

Fig. 1. Applying floating booms in practice. 


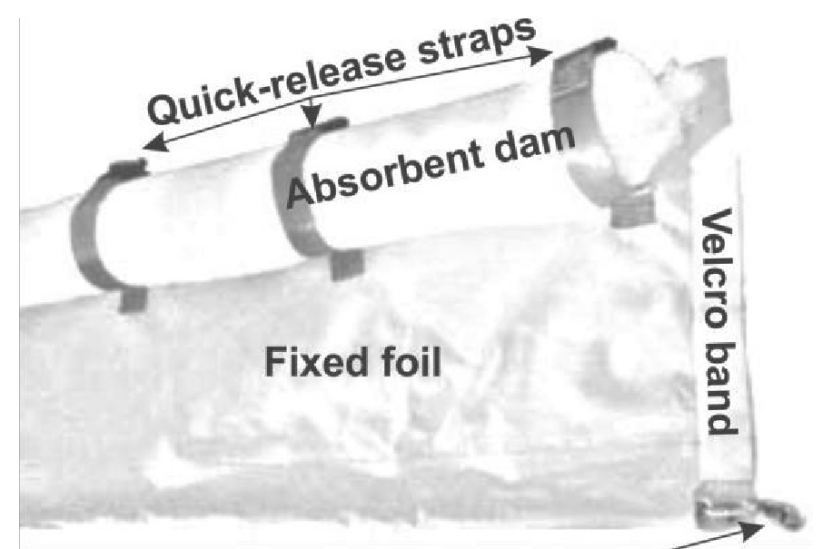

\section{Steel chain terminated by a carabiner to connect the dams in them}

Fig. 2. Floating boom structure.

adsorbents that are capable of floating on the water, not absorbing water, greater absorbing of petroleum substances and forming rigid suspensions.

Captured petroleum substances in adsorbing booms and on textiles or in the form of a formed suspension are disposed of by approved recycling processes or sequential decay by microorganisms in order to reduce the burden on the environment so that the selected procedures are in accordance with Act No. 223/2001 Coll. on Waste and on Amendments to Certain Acts as amended (Waste Act 79/2015).

\section{Preparing the Boom}

After notification of oil-based pollutant leakage to a water surface, especially if the substances leak into a watercourse, an intervention officer has to determine the place of installation of the floating boom, sufficiently distant from the site of contamination with respect to flow speed and time required for unpacking the floating boom. The speed of the water flow for the inflatable plastic floating boom shall be no greater than $0.5 \mathrm{~m} / \mathrm{s}$ and for the fixed boom up to $0.75 \mathrm{~m} / \mathrm{s}$; otherwise the entrained oil product may be carried along by the water stream under the plunged edge of the floating boom.

When selecting the terrain for positioning the floating boom, the emphasis is placed on the width of a watercourse and access to water itself, with the choice of where a watercourse flow is slow and where it is good access to a watercourse. If there is soft terrain, the bank must be reinforced for the truck, which picks up captured substances for disposal. As long-term work is required, it is necessary to ensure the lighting of the workplace simultaneously in order to ensure the accommodation, or the replacement of the floating boom operators and the services related to all the logistics activities.

Even though there is a stable interface between oil and water, the oil can be pulled down by a swirl under the floating boom. The oil substance is pushed out of

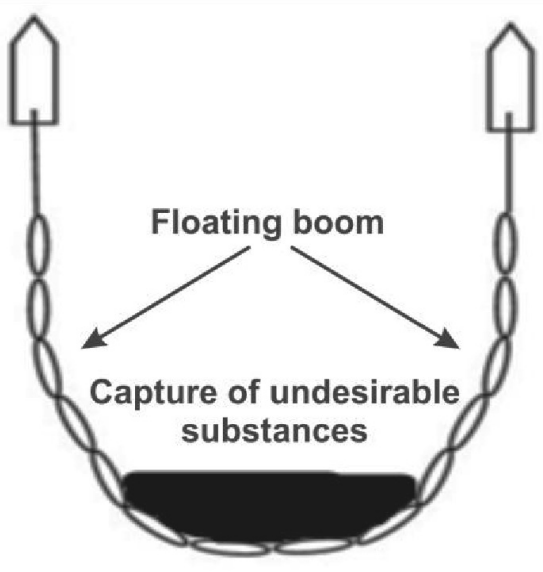

Fig. 3. U-shaped floating boom [28].

the water stream axis evenly to both banks, and forming water swirls carry away the oil under the water level by installing the floating boom. At a higher flow rate, the floating boom is obviously bent into a U-shape, and the sorbent cannot be collected (Fig. 3). There is the possibility of creating waves that influence the depth of the plunge of the floating boom on larger watercourses. During windy weather, the unloaded floating boom may be lifted. In the case of double-chamber foil coating booms, they can be air-drawn or extrude to damage the welds between the chambers. If fastening straps of floating booms become moistened, the straps may loosen. Hazardous places are located where the floating boom can be damaged when it is being prepared for installation (sharp stones, shrubs, etc.).

Foil double-chamber floating booms may be damaged when stacked on the water level and consequently by difficult shaping of the particular chambers. When applying the floating booms, floating objects on the water level can damage booms. It is appropriate to choose and install at least a second boom made with more resistant material. It is also necessary to ensure the regular control and removal of harmful substances when the boom is permanently attached. The oil spots may move on the water level in the wind direction and also upstream.

\section{Applying the Method of Using Floating Booms in Specific Positions}

Positioning of the floating boom is the basis for solving an accident on a watercourse (Fig. 4). It is important to recognize the appropriate and inappropriate flow for placing the boom. In very fast streams, the dangerous substance can overflow through the floating boom, so it is important to find a better place to catch the harmful substance.

It is necessary to know the number of parameters by which it is possible to calculate the resistance forces affecting the floating boom for the proper selection of the floating booms and their use in practice. Such 


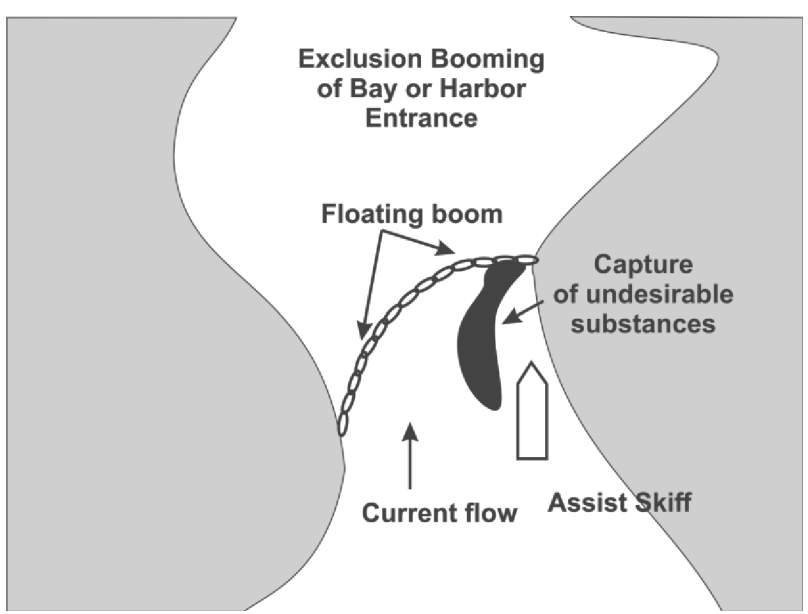

Fig. 4. Perpendicular view of a floating boom [28].

an analysis was created for selected rivers in a given region of Eastern Slovakia, where conditions of use were established as part of defining parameters of the floating boom for the needs of the practice. Our paper deals with the application procedure of the floating booms on selected rivers of Eastern Slovakia, where the parameters for remedying emergency accidents are set in extreme conditions.

\section{Model Situation of Environmental Accidents on Selected Rivers}

It is necessary to have the right amount of the floating booms that meet the parameters in order to resist the pressure at a certain speed of a river in the case of an ecological accident on a watercourse caused by oil products (Table 1). It is essential to do a survey of the water flows and, on this basis, to make calculations for correct choice of the type of floating boom that corresponds to the given conditions when selecting the floating booms for the need to clean up an ecological accident (Fig. 5). The maximum velocity of the water flow is taken into account in the calculations, which are usually in the narrowest place of the trough, and on this basis the calculation of the resistance force is provided to affect the floating boom.

\section{External Flows of a Riverside}

We selected Bodrog riverside, which includes the river flows listed in Table 1 for the prepared model situation.

The velocity or the maximum flow rate is essential to know in order to calculate the resistance force effecting the floating boom. There are flows of rivers during the entire observation period and of the last observation period in particular months in Table 1 .

The following formula can be used for the fast calculation and indicative load that effects the floating boom at the angle from $10^{\circ}$ to $30^{\circ}$ to the flow (1) [31]. a)

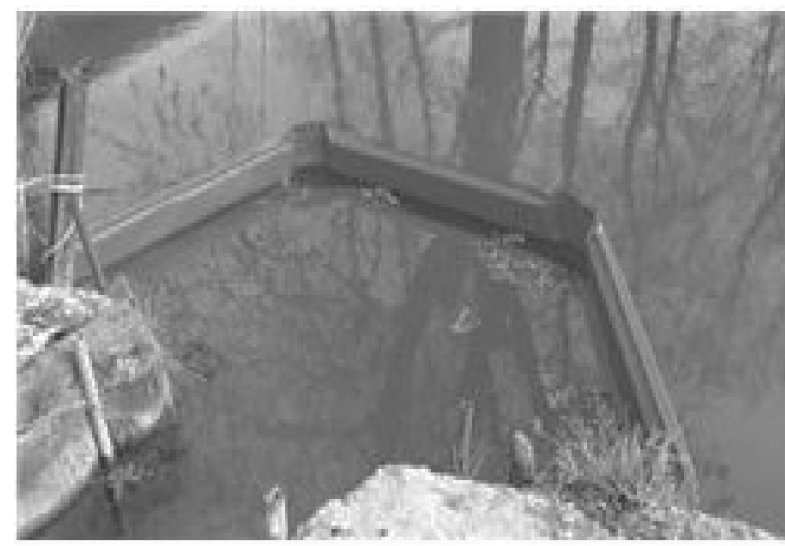

b)

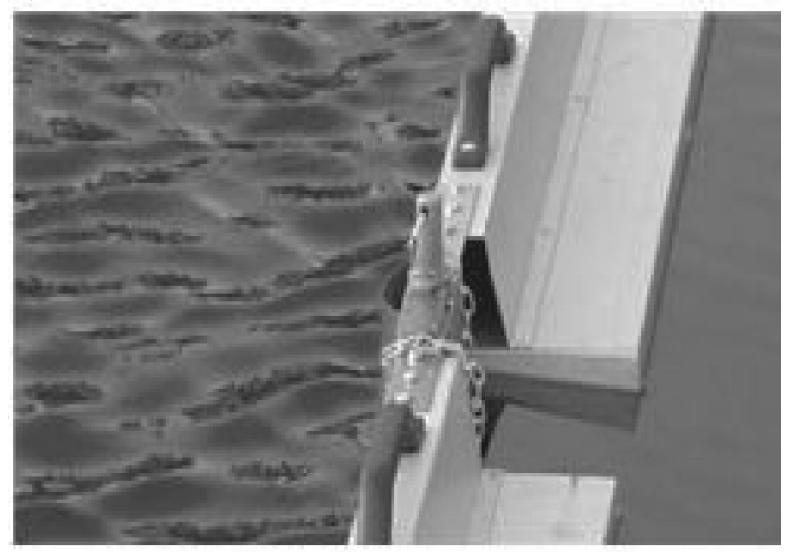

c)

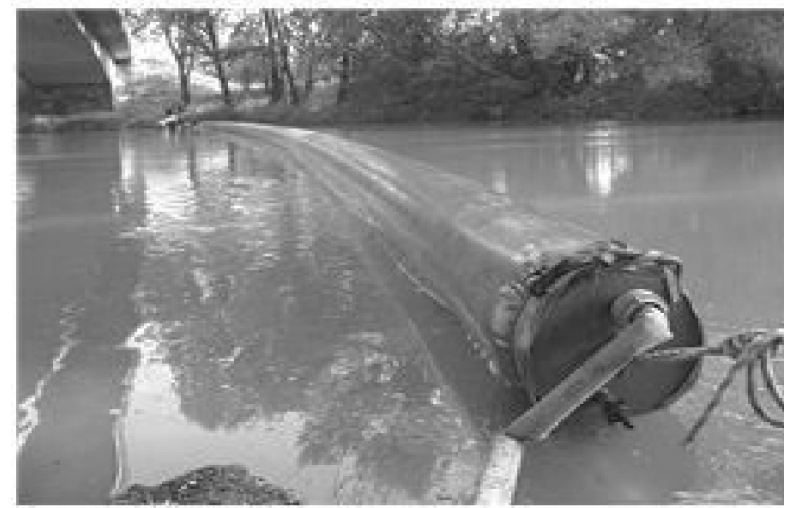

d)

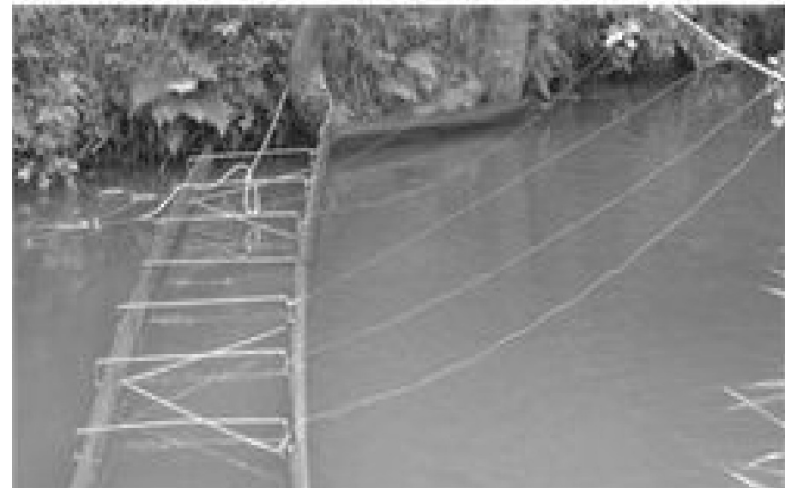

Fig. 5. Types of floating booms [29]: a) Light floating boom for slower water flows, b) Metal floating boom, c) Inflatable floating boom - double chamber, d) Special floating boom - type ladder. 
Table 1. Extreme flow values at selected riversides [30].

\begin{tabular}{|c|c|c|c|c|c|c|c|c|c|c|c|c|c|}
\hline \multicolumn{14}{|c|}{ Average monthly and extreme flows $\mathrm{Q}\left[\mathrm{m}^{3} \cdot \mathrm{s}^{-1}\right]$} \\
\hline Month & I & II & III & IV & V & VI & VII & VIII & IX & $\mathrm{X}$ & XI & XII & Year \\
\hline 9170 & \multicolumn{13}{|c|}{ Place 1; River 1; Positioning: 23.30; Surface: 250.04} \\
\hline Q & 3.408 & 5.066 & 2.512 & 1.601 & 1.611 & 0.96 & 0.61 & 0.704 & 0.789 & 1.089 & 1.188 & 0.564 & 1.653 \\
\hline \multicolumn{14}{|c|}{ Q max: 87.59; Q $\max 57$ years: 220; Q min: 0.458 ; Q min 57 years: 0.05} \\
\hline 9230 & \multicolumn{13}{|c|}{ Place 2; River 2; Positioning: 66.60; Surface: 1272.40} \\
\hline Q & 20.53 & 21.15 & 11.81 & 9.01 & 7.166 & 3.251 & 1.78 & 1.264 & 1.745 & 3.083 & 6.016 & 5.78 & 7.634 \\
\hline \multicolumn{14}{|c|}{ Q max: 313.1; Q $\max 47$ years: 663.9; Q min: 1.096; Q min 47 years: 0.538} \\
\hline 9240 & \multicolumn{13}{|c|}{ Place 3; River 3; Positioning: 39.20; Surface:1450.07 } \\
\hline Q & 13.35 & 17.02 & 11.52 & 8.704 & 5.645 & 3.715 & 1.782 & 1.197 & 1.542 & 1.902 & 2.339 & 2.842 & 5.893 \\
\hline \multicolumn{14}{|c|}{ Q max: 50.36; Q $\max 83$ years: 457; Q min: 0.619; Q $\min 83$ years: 0.245} \\
\hline 9450 & \multicolumn{13}{|c|}{ Place 4; River 4; Positioning: 103.50; Surface: 325.80} \\
\hline Q & 3.216 & 4.405 & 5.37 & 3.092 & 2.878 & 1.763 & 1.061 & 0.643 & 0.684 & 0.931 & 1.138 & 2.033 & 2.257 \\
\hline \multicolumn{14}{|c|}{ Q max: 29.73; Q $\max 47$ years: 351.2; Q min: 0.465 ; Q min 47 years: 0.11} \\
\hline 9580 & \multicolumn{13}{|c|}{ Place 5; River 5; Positioning: 117.30; Surface: 167.5} \\
\hline Q & 2.759 & 2.346 & 1.958 & 1.008 & 1.437 & 0.665 & 0.354 & 0.183 & 0.12 & 0.186 & 0.591 & 1.137 & 1.057 \\
\hline \multicolumn{14}{|c|}{ Q max: 53.38; Q $\max 52$ years: 420; Q min: 0.042; Q min 52 years: 0.04} \\
\hline 9590 & \multicolumn{13}{|c|}{ Place 6; River 6; Positioning: 0.60; Surface: 184.70} \\
\hline Q & 3.673 & 3.608 & 3.234 & 1.5 & 2.596 & 0.819 & 0.376 & 0.216 & 0.249 & 0.387 & 1.035 & 1.696 & 1.607 \\
\hline \multicolumn{14}{|c|}{ Q max: 49.45; Q max 52 years: 400; Q min: 0.13; Q min 52 years: 0.048} \\
\hline 9600 & \multicolumn{13}{|c|}{ Place 7; River 7; Positioning: 102.60; Surface: 578.40} \\
\hline Q & 10.47 & 9.51 & 7.369 & 3.512 & 5.434 & 2.157 & 0.948 & 0.503 & 0.555 & 0.904 & 2.32 & 3.866 & 3.937 \\
\hline \multicolumn{14}{|c|}{ Q max: 150.1; Q $\max 47$ years: 550; Q min: 0.279; Q min 47 years: 0.166} \\
\hline 9650 & \multicolumn{13}{|c|}{ Place 8; River 8; Positioning: 29.20; Surface: 2885.80} \\
\hline Q & 22.9 & 28.88 & 28.88 & 16.08 & 16.64 & 12.467 & 8.941 & 8.552 & 8.06 & 9.208 & 10.25 & 10.64 & 14.5 \\
\hline & & & 0 & O & ye & 772; Q & in: 6.5 & Q min & 3 yec & 1.49 & & & \\
\hline
\end{tabular}

$$
T=K * A * v^{2}
$$

...where:

$T=$ resistance force $(\mathrm{N})$

$K=$ constant, force acting on the surface at a certain speed (N.m.s ${ }^{-1}$ )

$A=$ the protruding surface of the plunged part of the boom $\left(\mathrm{m}^{2}\right)$

$v=$ flow speed $\left(\mathrm{m} . \mathrm{s}^{-1}\right)$

In the case of calm water, it is recommended to use the value of 2 for $K$, which represents the force effecting the surface at a certain speed. In the case of running water, it is recommended to use the value of 3 or 4 for $K$ [31].

The proposed protruding floating boom surface was calculated based on design of the floating boom and its length perpendicular to the water flow (2).

$$
A=d \times l \times \sin \alpha
$$

...where:

$A=$ surface of the plunged part of the boom $\left(\mathrm{m}^{2}\right)$

$d=$ width of the floating boom (plunged part) (m)

$l=$ length of the floating boom $(30.48 \mathrm{~m})$

$\alpha=$ angle of deflection $\left(10^{\circ}, 20^{\circ}, 30^{\circ}\right)$

Because of the greater number of calculations, the example of typical procedure for the parameters of River 1 will be provided in the paper. Other calculations for Rivers 2-5 are limited to the results only.

\section{Calculating River Speed}

\section{Snina-River Cirocha}

The maximum flow during the entire observation period was $\mathrm{Q}=220 \mathrm{~m}^{3} \cdot \mathrm{s}^{-1}$ [30] and the cross section flow is $\mathrm{S}=12 \mathrm{~m}^{2}$. The flow rate is calculated by using formula (3). 
Table 2. Size of the plunged part of the boom.

\begin{tabular}{|c|c|}
\hline \multicolumn{2}{|c|}{ The size of the plunged part of the floating boom } \\
\hline MZ 90 & $500 \mathrm{~mm}$ \\
\hline MZ 120 & $370 \mathrm{~mm}$ \\
\hline
\end{tabular}

$$
Q=v \times S
$$

$v=Q / S$

$v=220 / 12$

$v=18 \mathrm{~m} \cdot \mathrm{s}^{-1}$

\section{Resistance Force Calculation (T)}

The most common types of floating booms in the Košice and Prešov regions are MZ90 and MZ120 (Table 2).

$$
\begin{gathered}
\text { Snina }- \text { River Cirocha } \\
\text { For MZ } 90 \\
\mathrm{~T}=\mathrm{K} \times \mathrm{A} \times \mathrm{v}^{2} \\
\mathrm{~T}=4 \times 0.8 \times 35^{2} \\
\mathrm{~T}=3920 \mathrm{lbf}=17400 \mathrm{~N} \\
\mathrm{~A}=\mathrm{d} \times 1 \times \sin \theta \\
\mathrm{A}=1.64 \times 0.98 \times \sin 30^{\circ} \\
\mathrm{A}=0.8 \mathrm{ft}^{2}=0.244 \mathrm{~m}^{2}
\end{gathered}
$$

\section{Results, Discussion and Conclusions}

It is clear from the results presented in the individual calculations that the flow speed of a particular watercourse directly influences the speed at which dangerous substances flow. It also influences the selection of technical means used for capturing and collecting hazardous substances. It is necessary to take into account the indirect impacts that influence the effective use of the technical means. These indirect impacts are, e.g., atmospheric conditions, air and water temperature, meteorological conditions such as wind speed and its direction, air humidity and pressure, storm, snowfall, amount of contamination, sediments and feculences in a watercourse, and other limitation conditions that are specific to particular extraordinary events.

These presented calculations can be universally applied to different types of watercourses that have the character of continuous flowing rivers.

Despite findings from the research and individual analysis of watercourses in the Bodrog riverside, open questions remain: What to do in the case of the leakage of dangerous substance on stagnant watercourses or cascading watercourses where the flow is much larger? The answer to this question gives us the opposite view of the operational management of the intervention to eliminate or mitigate the consequences of an extraordinary accidental event where, in this case, it is necessary to interfere with the use of either towing or collecting barges where the speed of these barges must be at a similar speed as the watercourse flow.

In this case, depending on the type, extent and size of the leakage of the hazardous substance, it is necessary to choose the correct management tactics and apply the results from the calculations and to look at the saving activities with the opposite view: the stationary, anchoring point for the floating booms will not be a riverbank, but the water itself and the speed of either towing or collecting barges will be the flow of a watercourse itself.

Table 3. Flows of selected rivers and defined values of the size of the forces affecting the floating booms.

\begin{tabular}{|c|c|c|c|c|}
\hline RIVER & $\begin{array}{c}\text { Calculation of particular } \\
\text { rivers speed }\left[\mathrm{m} \cdot \mathrm{s}^{-1}\right]\end{array}$ & $\begin{array}{c}\text { MAXIMUM FLOW }\left[\mathrm{m}^{3} \cdot \mathrm{s}^{-1}\right] \\
\text { (during the observed period) }\end{array}$ & $\begin{array}{c}\text { MINIMUM FLOW }\left[\mathrm{m}^{3} \cdot \mathrm{s}^{-1}\right] \\
\text { (during the observed period) }\end{array}$ & $\begin{array}{c}\text { Resistance force } \\
{[\mathrm{N}]}\end{array}$ \\
\hline $\begin{array}{l}\text { Place 1 } \\
\text { River 1 }\end{array}$ & 18 & 220 & 0.05 & $\begin{array}{c}\text { for MZ90: } 17400 \\
\text { for MZ120: } 13000\end{array}$ \\
\hline $\begin{array}{l}\text { Place 2 } \\
\text { River 2 }\end{array}$ & 4.14 & 663.9 & 0.538 & $\begin{array}{c}\text { for MZ90: } 911 \\
\text { for MZ120: } 683\end{array}$ \\
\hline $\begin{array}{l}\text { Place 3 } \\
\text { River 3 }\end{array}$ & 4.76 & 457 & 0.245 & $\begin{array}{c}\text { for MZ90: } 1217 \\
\text { for MZ120: } 913\end{array}$ \\
\hline $\begin{array}{l}\text { Place 4 } \\
\text { River 4 }\end{array}$ & 4.9 & 351.2 & 0.11 & $\begin{array}{c}\text { for MZ90: } 1285 \\
\text { for MZ120: } 963\end{array}$ \\
\hline $\begin{array}{l}\text { Place 5 } \\
\text { River 5 }\end{array}$ & 6 & 420 & 0.04 & $\begin{array}{c}\text { for MZ90: } 1915 \\
\text { for MZ120: } 1436\end{array}$ \\
\hline $\begin{array}{l}\text { Place 6 } \\
\text { River 6 }\end{array}$ & 32 & 400 & 0.048 & $\begin{array}{c}\text { for MZ90: } 54717 \\
\text { for MZ120: } 41038\end{array}$ \\
\hline $\begin{array}{l}\text { Place 7 } \\
\text { River 7 }\end{array}$ & 12.5 & 550000 & 0.166 & $\begin{array}{c}\text { for MZ90: } 7694 \\
\text { for MZ120: } 5770\end{array}$ \\
\hline $\begin{array}{l}\text { Place 8 } \\
\text { River 8 }\end{array}$ & 38.6 & 772000 & 1.49 & $\begin{array}{c}\text { for MZ90: } 80068 \\
\text { for MZ120: } 60051\end{array}$ \\
\hline
\end{tabular}


Responding to this question, there are other open sub-questions: how to perform the intervention on standing water streams (dams, lakes, ponds, seas, oceans), where some intervention tactics are chosen, and where authors will address the issue of an operational solution in further research.

\section{Conclusions}

Floating booms can be used to protect environmentally sensitive or socially economically important river estuaries or watercourses from pollution by hazardous substances. Successful and effective use of floating booms depends primarily on the careful preparation and practical verification of particular operational and flood plans for each site of use. These plans must clearly explain the reasons for selecting the place of use, preferring the sites for simple use of the booms and providing clear information to facilitate work with technical means.

The preparation of operational and flood plans for the use of the floating booms is an important task to be done by staff and members with excellent technical and theoretical knowledge of the subject. It is necessary to test these plans in a real environment and, subsequently, if the deficiencies are identified, the plans have to be changed according to the location requirements of the future use of the technical means when processing particular operational and threat plans. In cases of impossibility to deploy the technical means at given places it is necessary to record this fact in the particular plan with all the reasons and the facts for the impossibility to use material equipment. This will prevent the waste of time and resources in the future in the event of unsuccessful deployment when an accident occurs on a watercourse.

Particular operational plans need to be integrated into the emergency response scenarios for all emergency services, crisis management authorities, government and self-government bodies and environmental authorities for the needs of early and successful solutions of an extraordinary accident event.

\section{Acknowledgements}

The submitted paper is part of the project "Implementation of innovative instruments for increasing the quality of higher education in the 5.2.52 industrial engineering field of study" (KEGA 030TUKE-4/2017), funded by the Slovak Cultural and Education Grant Agency.

\section{Conflict of Interest}

The authors declare no conflict of interest.

\section{References}

1. MALINDZAKOVA M., STRAKA M., ROSOVA A., KANUCHOVA M., TREBUNA P. Modeling the process for incineration of municipal waste. Przemysl Chemiczny, 94 (8), 1260, 2015.

2. HAVERLAND J., BESTA P. Determination of importance of ore raw materials evaluation criteria. Acta logistica, $\mathbf{5}$ (2), 39, 2018.

3. STRAKA M., MALINDZAK D. Period defining for creation of production planning of firm Alfa Foils, a.s. Acta Montanistica Slovaca, 14 (1), 121, 2009.

4. BUŠA M., KAZIMÍROVÁ I., PAŠKA M., PUŠKAŠ E., FARKAS C. Planning and economic perspective of material flow. Acta logistica, 5 (1), 25, 2018.

5. TREBUNA P., STRAKA M., ROSOVA A., MALINDZAKOVA M. Petri nets as a tool for production streamlining in plastics processing. Przemysl Chemiczny, 94 (9), 1605, 2015.

6. ZEY S., NOWROOZPOUR A., LACHHAB A., MARTINEZ E., ETTEMA R. Wall-porosity effects on sediment deposition and scour at a deflector wall in an alluvial channel. Journal of Hydraulic Engineering, 144 (3), March 2018.

7. SHI Y., LI S., CHEN H., HE M., SHAO S. Improved SPH simulation of spilled oil contained by flexible floating boom under wave-current coupling condition. Journal of Fluids and Structures, 76 (January), 272, 2018.

8. SHI Y., LI S., ZHANG H., PENG S., CHEN H., ZHOU R., MAO T. Numerical modeling of floating oil boom motions in wave-current coupling conditions. Journal of Ocean University of China, 16 (4), 602, 2017.

9. GAPINGSI G.E., KORBAS R., SANTOS M. Modelling and Control of a Flexible Floating Boom: First Approach. IFAC-Papers, $\mathbf{5 0}$ (1), 13108, 2017.

10. MUTTIN F., CAMPBELL R., OUANSAFI A., BENELMOSTAFA Y. Numerical modelling and experimentation of oil-spill curtain booms: Application to a harbor, AIP Conference Proceedings, 1798, 27 January 2017.

11. PERMINOVA O.M., LOBANOVA G.A. A logistic approach to establishing balanced scorecard of Russian oil-producing service organizations. Acta logistica, 5 (1), $1,2018$.

12. STRAKA M., MALINDZAK D. Algorithms of capacity balancing of printing machineries for Alfa Foils, a.s. planning system. Acta Montanistica Slovaca, 14 (1), 98, 2009.

13. DUPLÁKOVÁ D., RADCHENKO S., KNAPČÍKOVÁ L., HATALA M., DUPLÁK J. Application of simulation tool for scheduling in engineering. Acta Simulatio, 3 (1), $5,2017$.

14. WASILEWSKI J., SZCZEPANIK M., BURSKI Z. Biohazards in International Road Transport Logistics in the Polish Part of the European Union's Eastern Border. Polish Journal of Environmental Studies, 27 (4), 1805, 2018.

15. ZIMON D., DOMINGUES P. Proposal of a Concept for Improving the Sustainable Management of Supply Chains in the Textile Industry. Fibres \& Textiles in Eastern Europe, 26 (2), 8, 2018.

16. STRAKA M. Alfa, a.s. distribution logistics system. Acta Montanistica Slovaca, 15 (SI1), 34, 2010. 
17. UNCUMUSAOĞLU A.A., AKKAN T. Assessment of Water Quality of Yağlidere Stream (Turkey) Using Multivariate Statistical Techniquess. Polish Journal of Environmental Studies, 26 (4), 1715, 2017.

18. TSANG G. Ice conditions and the proposed containment and removal of spilled oil on St. Clair and Detroit Rivers. Inland Waters Directorate, Canada Centre for Inland Waters, 1975.

19. DOMMERGUES B., BRAMBINI R., METTLER R., ABIZA Z., SAINTE - ROSE B. Hydrodynamics and capture efficiency of plastic cleanup booms: Part II, 2D vertical capture efficiency and CFD validation. Conference: OMAE, 2017.

20. BRAMBINI R., DOMMERGUES B., MARAL H., SAINTE-ROSE B. Hydrodynamics and capture efficiency of plastic cleanup booms: Part I, experiments and dynamic analysis. Conference: OMAE, 2017.

21. CHEN Z., CUERVO D.P., MÜLLER J.A., WIESSNER A., KÖSER H., VYMAZAL J., KÄSTNER M., KUSCHK P. Hydroponic root mats for wastewater treatment - a review. Environmental Science and Pollution Research, 23 (16), 15911, 2016.

22. SAINTE-ROSE B., LEBRETON L., DE LIMA REGO J., KLEISSEN F., REISSER J. Multi-scale numerical analysis of the field efficiency of an ocean plastic cleanup array. Conference: OMAE, 2016.

23. CASTRO A., PÉREZ J.L., RABUÑAL J.R., IGLESIAS G. Genetic programming and floating boom performance. Ocean Engineering, 104 (18), 310, 2015.
24. GIRON-SIERA J.M., GHEORGHITA A.T., ANGULO G., JIMENEZ J.F. Preparing the automatic spill recovery by two unmanned boats towing a boom: Development with scale experiments. Ocean Engineering, 95, 23, 2015.

25. GASPERI J., DRIS R., BONIN T., ROCHER V., TASSIN B. Assessment of floating plastic debris in surface water along the Seine River. Environmental pollution (Barking, Essex : 1987), 195, 163, 2014.

26. SHI Y., LI S., CHEN H., HE M., SHAO S. Improved SPH simulation of spilled oil contained by flexible floating boom under wave-current coupling condition. Journal of Fluids and Structures, 76, 272, 2018.

27. SHI Y., LI S., ZHANG H., PENG S., CHEN H. Experimental studies on performances of flexible floating oil booms in coupled wave-current flow. Applied Ocean Research, 69, 38, 2017.

28. SEAPRO Response Operations Manual, Booming and Anchoring. Available online: http://www.seapro.org/pdf docs/Booming\%20and\%20Anchoring.pdf (accessed on 11.07.2018).

29. REOAMOS Slovakia, Light floating boom for slower water flows. Available online: https://www.reoamos.sk/lahkanorna-stena-pre-pomalsie-vodne-toky/d-4591/ (accessed on 11.07.2018).

30. Extreme flow values at selected rivers, Slovak Hydrometeorological Institute - SHMU, hydrological service, 2018.

31. MANDLER M.B. Oil Spill Response in Fast Currents a Field Guide. United States Coast Guard Research \& Development Center, Report No. CG-D-01-02, 2001. 